\title{
Platelet reactivity expressed as a novel platelet reactivity score is associated with higher inflammatory state after coronary artery bypass grafting
}

\author{
Mirosław Wilczyński ${ }^{1}$, Michał Krejca $^{1}$, Piotr Stepinski ${ }^{1}$, Marcin Rozalski², Jacek Golanski ${ }^{2}$
}

\author{
${ }^{1}$ Department of Cardiac Surgery, Chair of Cardiology and Cardiac Surgery, \\ Medical University of Lodz, Lodz, Poland \\ 2Department of Haemostasis and Haemostatic Disorders, Medical University of Lodz, \\ Lodz, Poland
}

Submitted: 28 May 2019; Accepted: 19 August 2019

Online publication: 12 December 2019

Arch Med Sci 2023; 19 (2): 392-400

DOI: https://doi.org/10.5114/aoms.2019.90470

Copyright (c) 2019 Termedia \& Banach

\begin{abstract}
Introduction: Despite therapy, patients operated using a cardiopulmonary bypass demonstrate increased platelet aggregation, which rebounds to above preoperative levels. The aim of the study was to test the interaction between platelet reactivity/activation and selected inflammatory markers in the post-operative period.

Material and methods: In total, 103 patients with non-ST elevation acute coronary syndrome (NSTE-ACS) who were not eligible for percutaneous coronary interventions $(\mathrm{PCl})$, and required urgent revascularization, were included. Platelet reactivity was measured using the PFA-100 platelet analyser, multiple electrode aggregometry, and was expressed as a novel platelet reactivity score (PRS). Patients were divided using their PRS scores into high platelet relativity or low platelet reactivity subgroups (HPR or LPR). Platelet basal activation was measured using immunoassays for soluble P-selectin and soluble CD40L. We measured high-sensitivity C-reactive protein (CRP), and used immunoassays for tumour necrosis factor $\alpha$ (TNF- $\alpha$ ) and interleukin 6 (IL-6) as inflammation markers.

Results: Significant differences between HPR and LPR groups were found for CRP (mg/l): 81.5 vs. 44.6, $p<0.02$; and TNF- $\alpha$ (pg/l): 3.51 vs. $2.37, p<0.02$. A significant association was found between CRP, TNF- $\alpha$, IL- 6 and platelet reactivity (platelet reactivity score). Cohen's $\kappa$ showed: $C R P=0.49, p<0.0001$, TNF- $\alpha=0.37, p<0.002$. Perioperative myocardial infarction and rhythm disturbances occurred more frequently in the high platelet reactivity group: $7(16.3 \%)$ vs. $2(3.3 \%), p<0.04$, and $9(20.9 \%)$ vs. $4(6.7 \%), p<0.04$, respectively. Conclusions: Inflammatory parameters CRP and TNF- $\alpha$ are strongly associated with platelet reactivity (expressed as PRS) in cardiopulmonary bypass graft patients. Platelet hyperreactivity in the early post-operative period combined with a systemic inflammatory state correlates with a higher risk of post-operative rhythm disturbances and myocardial infarction.
\end{abstract}

Key words: platelet reactivity, platelet activation, inflammation, coronary artery bypass grafting, cardiopulmonary bypass.

\section{Introduction}

Antiplatelet treatment has proved to be effective in preventing bypass occlusion after coronary artery bypass grafting (CABG). Despite therapy, patients operated using a cardiopulmonary bypass showed

\author{
Corresponding author: \\ Dr. Jacek Golański \\ Department of Haemostasis \\ and Haemostatic Disorders \\ Chair of Biomedical Sciences \\ Medical University of Lodz \\ 6/8 Mazowiecka St \\ 92-215 Lodz, Poland \\ Phone: +48 422725720 \\ E-mail: jacek.golanski@umed. \\ lodz.pl
}


increased platelet aggregation that rebounded to above preoperative levels [1, 2]. Considering the mechanism of early graft failure, it seems logical that potent platelet inhibition may improve graft patency [3-5]. By contrast, it is known that an impaired response to antiplatelet therapy underlies the increased risk of post-operative occlusions and can even result in death after CABG surgery [6]. Several potential explanations have been proposed for the nature of high on-treatment platelet reactivity, including modifiable factors: too low doses of anti- platelet drugs, high platelet turnover, oxidative stress, dyslipidaemia and inflammation [7-12]. Coronary artery bypass grafting surgery itself is associated with excessive activation of platelets, which results in stimulation of the production and release of young platelets [2, 13, 14].

It is noteworthy that platelet reactivity is strongly dependent on modifiable factors, especially on the inflammatory state $[12,15,16]$. The inflammation process, which is associated with CABG as a result of cardiopulmonary bypass, is affected by many factors, including surgical trauma, blood contact with the cardiopulmonary bypass (CPB) device's artificial surfaces, as well as ischaemia and reperfusion injury. The pro-inflammatory cytokines interleukin (IL)- 6 and IL-8, tumour necrosis factor- $\alpha$ (TNF- $\alpha$ ), anti-inflammatory IL-10, and C-reactive protein (CRP) were found at increased levels following CABG [17].

Coronary artery bypass grafting surgery is associated with a systemic inflammatory response, endothelial damage and platelet activation, regardless of whether a CPB has been performed [18-20]. A number of publications indicate that this augmentation of platelet reactivity largely depends on a set of environmental factors, including the inflammatory state $[15,21]$. The association between preoperative inflammatory parameters and early graft occlusion, as well as cardiovascular events following coronary artery bypass grafting, has not, however, been fully elucidated [22]. C-reactive protein is a powerful independent predictor of cardiovascular events in patients with coronary artery disease. Recent clinical trials targeting CRP have shown a reduction in major adverse cardiovascular events (MACE) after an acute coronary syndrome (ACS). Inflammation could be linked to high platelet reactivity (HPR), which is an independent predictor of MACE in patients with ACS [15]. A relation has been observed between CRP concentration and in-hospital outcome, following coronary artery bypass grafting [23]. It seems that a rise in the CRP level, as an inflammation marker, may be associated with transient platelet hyperactivity after CABG.

Therefore, the aim of this study was to evaluate the effect of an inflammatory state (measured by
CRP, IL- 6 and TNF- $\alpha$ levels) on platelet reactivity in a short postoperative period ( $6^{\text {th }}$ day) using two different platelet assays and to analyse the results comprehensively.

\section{Material and methods}

\section{Patients}

In total, 140 patients with NSTE-ACS, who were not eligible for $\mathrm{PCl}$ and required urgent revascularization, were enrolled in the study (source population). All CABG procedures were performed at the First Department of Cardiac Surgery, Medical University of Silesia in Katowice (Poland). Patients meeting inclusion criteria were enrolled consecutively. Patients presenting at least two of the following criteria were included in the study: 1) symptoms of chest pain lasting for at least 20 min within a period of $24 \mathrm{~h}$ preceding the coronary angiography; 2) elevated troponin levels; 3) ST-segment depression of at least $0.1 \mathrm{mV}$ or a negative $\mathrm{T}$ wave of at least $0.2 \mathrm{mV}$ in two or more contiguous leads. All the patients enrolled in the study presented with complex coronary lesions including left main disease, multiple-vessel disease or a coronary anatomy not amenable to $\mathrm{PCl}$, which was reflected by a SYNTAX score $>22$ points (intermediate and high risk).

The predefined exclusion criteria were: chest pain longer than $48 \mathrm{~h}$, ST segment elevation, oral pre-treatment with clopidogrel, age over 80 years, percutaneous revascularization procedure within the previous 30 days, CABG within the previous 6 months, NYHA class IV heart failure preceding hospitalization, gastrointestinal or genitourinary bleeding within the previous 30 days, history of intracranial disorders (including stroke, primary and metastatic brain tumours and history of head trauma); major surgery or high level trauma within the previous 6 weeks; history of bleeding diathesis, thrombocytopenia defined as less than $100,000 \mathrm{PLT} / \mathrm{mm}^{3}$, anticoagulation with INR $\geq 1.8$, impairment of liver function, renal impairment with creatinine level > $1.5 \mathrm{mg} \%$, uncontrolled blood pressure exceeding 200/110 $\mathrm{mm} \mathrm{Hg}$, and hypersensitivity to any drug.

The characteristics of the overall (source) population of the study $(n=140)$ were: female sex: $40(28.6 \%)$ patients; age: $63.0 \pm 9.4$ years; body mass index (BMI) $28.2 \pm 3.9 \mathrm{~kg} / \mathrm{m}^{2}$; hypertension: 109 (77.9\%); dyslipidaemia: 132 (94.3\%); peripheral artery disease: 9 (6.4\%); diabetes mellitus: 35 (25.0\%); EuroSCORE: $5.6 \pm 2.0$ points. All the patients were on aspirin until the day of the operation. A complete set of all clinical and laboratory data was gathered for the target group $(n=103)$. The characteristics of this group are presented in detail in Table I. 
Table I. Characteristics of total group of coronary artery bypass grafting subjects and patients allocated to subgroups with high and low platelet reactivity (estimated using the platelet reactivity score) 6 days after the operation

\begin{tabular}{|c|c|c|c|c|}
\hline Variable & $\begin{array}{c}\text { Whole group } \\
n=103\end{array}$ & $\begin{array}{l}\text { High platelet reactivity } \\
\qquad n=43\end{array}$ & $\begin{array}{l}\text { Low platelet reactivity } \\
\qquad n=60\end{array}$ & $P$-value* \\
\hline Female sex (\%) & $35(34.0)$ & $15(34.5 \%)$ & $20(33.3 \%)$ & ns \\
\hline Age [years] & $62.7 \pm 9.9$ & $61.0 \pm 10.9$ & $63.1 \pm 9.4$ & ns \\
\hline $\mathrm{BMI}\left[\mathrm{kg} / \mathrm{m}^{2}\right]$ & $27.7 \pm 3.3$ & $28.7 \pm 3.5$ & $27.6 \pm 3.2$ & ns \\
\hline Hypertension (\%) & $85(82.5)$ & $37(86.0 \%)$ & $48(80.0 \%)$ & ns \\
\hline Dyslipidaemia (\%) & $98(95.1)$ & $41(95.3 \%)$ & $57(95.0 \%)$ & ns \\
\hline Peripheral artery disease (\%) & $8(7.6)$ & $2(4.7 \%)$ & $6(10.0 \%)$ & ns \\
\hline Diabetes mellitus (\%) & $23(22.3)$ & $12(27.9 \%)$ & $11(18.3 \%)$ & ns \\
\hline EuroSCORE [points] & $5.8 \pm 2.0$ & $6.0 \pm 2.2$ & $5.7 \pm 1.9$ & ns \\
\hline Duration of CPB [min] & $87.4 \pm 21.6$ & $85.4 \pm 26.2$ & $88.3 \pm 23.3$ & ns \\
\hline Aorta clamping time $[\mathrm{min}]$ & $48.2 \pm 19.0$ & $47.3 \pm 19.0$ & $48.7 \pm 13.9$ & ns \\
\hline Postoperative blood drainage [ml] & $826 \pm 448$ & $814 \pm 491$ & $848 \pm 491$ & ns \\
\hline Need for PRBCs transfusion & $1.61 \pm 1.39$ & $1.60 \pm 1.29$ & $1.62 \pm 1.47$ & ns \\
\hline Need for FFP transfusion & $2.28 \pm 0.74$ & $2.28 \pm 0.70$ & $2.28 \pm 0.76$ & ns \\
\hline Need for PRP transfusion & $0.90 \pm 0.58$ & $1.16 \pm 0.69$ & $0.57 \pm 0.69$ & ns \\
\hline CK-MB [UI] & $\begin{array}{c}24.00 \\
(17.50-42.49)\end{array}$ & $\begin{array}{c}24.00 \\
(16.50-52.50)\end{array}$ & $\begin{array}{c}24.00 \\
(18.00-32.25)\end{array}$ & ns \\
\hline $\mathrm{Tnl}[\mathrm{ng} / \mathrm{ml}]$ & $\begin{array}{c}0.92 \\
(0.38-2.01) \\
\end{array}$ & $\begin{array}{c}0.99 \\
(0.43-2.45) \\
\end{array}$ & $\begin{array}{c}0.86 \\
(0.37-1.95) \\
\end{array}$ & ns \\
\hline Perioperative $\mathrm{MI}$ & $9(8.7 \%)$ & $7(16.3 \%)$ & $2(3.3 \%)$ & $<0.04$ \\
\hline Postoperative rhythm disturbances & $13(12.6 \%)$ & $9(20.9 \%)$ & $4(6.7 \%)$ & $<0.04$ \\
\hline $\mathrm{Hb}[\mathrm{g} / \mathrm{dll}]$ & $11.78 \pm 1.19$ & $11.82 \pm 1.20$ & $11.68 \pm 1.18$ & ns \\
\hline Leukocyte count $\left[\times 10^{9} / \mathrm{l}\right]$ & $9.75 \pm 1.37$ & $9.66 \pm 1.42$ & $9.87 \pm 1.26$ & ns \\
\hline Platelet count $\left[\times 10^{9} / I\right]$ & $227.8 \pm 80.9$ & $217.8 \pm 75.9$ & $236.7 \pm 84.7$ & ns \\
\hline Mean platelet volume [fl] & $10.38 \pm 1.49$ & $10.39 \pm 1.57$ & $10.35 \pm 1.47$ & ns \\
\hline IL-6 [pg/l] & $\begin{array}{c}22.8 \\
(14.4-31.4) \\
\end{array}$ & $\begin{array}{c}24.4 \\
(14.8-37.5) \\
\end{array}$ & $\begin{array}{c}21.4 \\
(13.2-30.0) \\
\end{array}$ & ns \\
\hline $\mathrm{CRP}[\mathrm{mg} / \mathrm{l}]$ & $\begin{array}{c}54.1 \\
(36.7-82.0)\end{array}$ & $\begin{array}{c}81.5 \\
(44.7-104.8)\end{array}$ & $\begin{array}{c}44.6 \\
(36.5-62.7)\end{array}$ & $<0.02$ \\
\hline TNF- $\alpha[p g / l]$ & $\begin{array}{c}2.59 \\
(2.16-4.15)\end{array}$ & $\begin{array}{c}3.51 \\
(2.38-5.25)\end{array}$ & $\begin{array}{c}2.37 \\
(1.77-3.10)\end{array}$ & $<0.02$ \\
\hline
\end{tabular}

Continuous data are presented as mean $\pm S D$ or as median (interquartile range: $L Q-U Q$ ). Categorical data are presented as absolute numbers and \%. Significance of differences was analyzed using Mann-Whitney U test (continuous data) or Fisher's exact test (categorical data). *Statistical significance of differences regards a comparison of the two subgroups. BMI-body mass index, CPB - cardiopulmonary bypass, PRBCs - packed red blood cells, FFP - fresh frozen plasma, PRP - platelet rich plazma, MI - myocardial infarction, Tnl - troponin I, $\mathrm{Hb}$ - hemoglobin, IL-6 - interleukin-6, CRP-C-reactive protein, TNF- $\alpha$-tumour necrosis factor- $\alpha$.

\section{Operative (surgery) techniques}

Anaesthesia was induced and maintained using standard procedures. A median sternotomy was performed and patients were placed on CPB, under mild hypothermia at $34^{\circ} \mathrm{C}$ and cold cardioplegia at a $4: 1$ ratio to protect against myocardial ischaemia. Unfractionated heparin was delivered intravenously at a dose of $300 \mathrm{U} / \mathrm{kg}$ and then again every $60 \mathrm{~min}$ of CPB to maintain an acti- vated clotting time of at least $480 \mathrm{~s}$. Immediately after CPB was ceased, heparin was reversed with protamine sulphate at a dose of $3 \mathrm{mg} / \mathrm{kg}$. Acetylsalicylic acid (aspirin) at a daily dose of $300 \mathrm{mg}$ was reinitiated after the procedure, subsequently reduced to a daily dose of $150 \mathrm{mg}$ on day 6 and maintained for the duration of the study. Clopidogrel at a daily dose of $75 \mathrm{mg}$ was administered to each patient 6 days after the procedure. 


\section{Blood collection}

Blood was collected by peripheral venipuncture into two plastic tubes (S-Monovette; Sarstedt, Nümbrecht, Germany). The first tube contained buffered 3.2\% sodium citrate (Becton Dickinson, Plymouth, United Kingdom) with a final citrate to blood ratio of $1: 9 \mathrm{vol} / \mathrm{vol}$, while the second contained $250 \mu \mathrm{g} / \mathrm{ml}$ hirudin (Refludan, Schering AG, Germany), yielding a final concentration of $25 \mu \mathrm{g} / \mathrm{ml}$ in the blood sample. Whole blood was kept at room temperature. Blood samples for complete blood cell counts were collected in $\mathrm{K}_{2}$ EDTA anticoagulated sample tubes. The samples were processed within $4 \mathrm{~h}$.

\section{Platelet reactivity}

\section{Determination of PFA-100 closure time}

The closure time (CT expressed in seconds, maximal recorded value of $300 \mathrm{~s}$ ) was measured using a PFA-100 flow analyser (Siemens Healthcare Diagnostics, Inc, Norwood, MA, USA). All blood samples were tested for closure times with collagen/epinephrine ( $\left.\mathrm{CT}_{\text {CEPP }}\right)$ and collagen/ADP ( $\left.\mathrm{CT}_{\text {CADP }}\right)$ cartridges in accordance with the manufacturer's instructions, at least 30 min but not more than $1 \mathrm{~h}$ after the blood was withdrawn. PFA-100 measurements were performed in duplicate, and mean CT values were calculated.

\section{Multiple electrode aggregometry}

Whole blood aggregation was measured using a 5-channel, semi-automatic, dual measurement aggregometer (Multiplate Analyzer; Roche Diagnostics $\mathrm{GmbH}$, Mannheim, Germany). The ADP Test (ADP; final concentration, $6.4 \mu \mathrm{mol}$ ) or AspiTest (arachidonic acid, final concentration, $0.5 \mathrm{mmol} / \mathrm{l}$ ) was added as a platelet agonist, and an increase in electrical impedance caused by the growing platelet attachment to the electrodes was recorded continuously for $10 \mathrm{~min}$. Platelet reactivity was expressed as the maximal aggregation (arbitrary units - AU).

\section{Platelet reactivity score}

In this paper, we suggest introducing a novel comprehensive score for assessing platelet reactivity: the platelet reactivity score (PRS). The rule for calculating PRS is shown below (medians are calculated on the basis of all the results of the given parameter ( $C T_{\text {CEPP }}, C_{\text {CADP }}$ ASPItest, ADPtest) in the studied group.

$\mathrm{CT}_{\text {CEPI }}<$ median: 1; $\mathrm{CT}_{\text {CEPI }} \geq$ median: 0

$\mathrm{CT}_{\text {CADP }}<$ median: $1 ; \mathrm{CT}_{\text {CADP }} \geq$ median: 0

ASPItest $>$ median: 1 ; ASPItest $\leq$ median: 0

ADPtest > median: 1; ADPtest $\leq$ median: 0

The PRS score range is from 0 to 4 , with a cut- off platelet reactivity score of $>2$. Patients were allocated to the high platelet reactivity (HPR) group or the low platelet reactivity (LPR) group (PRS $\leq 2$ ).

\section{Platelet activation}

Immunoassays for soluble P-selectin (soluble CD62) and soluble CD40L

To obtain plasma for immunoassays, EDTA blood was prepared following standard procedures and the samples were stored at $-50^{\circ} \mathrm{C}$ until analysis. Levels of sP-selectin and SCD40L in patients' plasma were measured using commercially available ELISA tests (respectively, Human P-Selectin/CD62P DuoSet ELISA Quantikine and Human CD40 Ligand/TNFSF5 Quantikine ELISA Kit; R\&D Systems, Minneapolis, Minnesota, USA). The intra-assay variability for the lower assay range was less than $10 \%$. The measurement ranges were $0-50 \mathrm{ng} / \mathrm{ml}$ for sCD62 and 62-4000 pg/ml for SCD40L.

\section{Inflammatory markers and other laboratory parameters}

CK-MB, high-sensitive troponin I (hTnl) and high-sensitivity C-reactive protein (hs-CRP) serum levels were measured using an ELISA test. To assess qualitative and quantitative changes in platelets the following parameters were analysed: mean platelet count (MPC), mean platelet volume (MPV) and large platelet concentration ratio (L-PCR). Cell blood counts were carried out using the Sysmex XE-2100 (Sysmex Corporation, Kobe, Kansai, Japan).

\section{Immunoassays for tumour necrosis factor- $\alpha$} and interleukin-6

To obtain serum for immunoassays, non-anticoagulated blood was prepared following standard procedures and samples were stored at $-50^{\circ} \mathrm{C}$ until analysis. Levels of TNF- $\alpha$ and IL- 6 in patients' serum were measured using commercially available ELISA tests (respectively, Human TNF-alpha Quantikine ELISA Kit and Human IL-6 Quantikine ELISA Kit, R\&D Systems, Minneapolis, Minnesota, USA). The intra-assay variability for the lower assay range was less than $10 \%$. The measurement ranges for TNF- $\alpha$ were $0.5-32 \mathrm{pg} / \mathrm{ml}$ and $3.1-300 \mathrm{pg} / \mathrm{ml}$ for IL-6.

\section{Measurement points}

Two time points were used to test all parameters: (T1) before CABG, (T2) 6 days after the surgery procedure.

\section{Statistical analysis}

Mean \pm SD are given for normally distributed variables. Medians and interquartile ranges ( $M e$, 
IQ) are given for other parameters showing departures from normality (according to the ShapiroWilk $W$ test). Simple paired comparisons were performed using unpaired Student $t$ test, while non-normally distributed variables were analysed using the Mann-Whitney $U$ test. Pearson's $\chi^{2}$ test with Yates correction (if necessary) was used for categorical data. Cohen's $\kappa$ coefficient was calculated as a measure of agreement. A $\kappa$ statistic value of $<0.4$ represents poor-to-fair agreement, a value of $0.41-0.60$ reflects moderate agreement, a value of $0.61-0.80$ is considered good agreement, and a $\kappa$ value of $0.81-1.0$ is considered very good agreement. The odds ratio (OR) and 95\% confidence interval $(\mathrm{Cl})$ were assessed to establish the correlation between PRS and inflammatory markers using logistic regression.

The statistical analysis was performed using Statistica 13.1 (StatSoft Inc., Tulsa, Oklahoma).

\section{Results}

\section{Patients and procedural characteristics}

Thirty-seven patients were excluded from the study due to incomplete laboratory parameters. In total, 103 NSTE-ACS patients, requiring urgent coronary artery bypass graft surgery, were included in the study. The characteristics of selected parameters in CABG patients before and 6 days after the operation are presented in Table II.

\section{Platelet reactivity and activation}

\section{on the $6^{\text {th }}$ day after the operation}

Platelet reactivity significantly increased in the postoperative period, as reflected by $\mathrm{CT}_{\text {CEPI }}$ and $\mathrm{CT}_{\text {CADP. }}$. In the case of arachidonic acid (ASPItest) and ADP- induced aggregation (ADPtest), there were no differences between the pre-operative period and on the $6^{\text {th }}$ day after CABG (Figure 1).

Platelet activation significantly increased in the post-operative period, as reflected by the elevated levels of soluble P-selectin and soluble CD40L (Figure 2).

\section{High platelet reactivity and low platelet reactivity groups}

There was no association between individual parameters (analysed alone) of platelet reactivity dependent on aspirin ( $\mathrm{CT}_{\mathrm{CEPP}}$, ASPItest) and a very low association between parameters of platelet reactivity dependent on $\mathrm{P} 2 \mathrm{Y} 12$ inhibitors (CT CADP ADPtest) and inflammatory markers. However, in the next approach, we used a complex, comprehensive score (the novel PRS) and divided the whole group into high platelet reactivity (PRS > 2; HPR; $n=43$ ) and low platelet reactivity (PRS $\leq 2$; LPR; $n=60$ ) subgroups. Using this approach, the elevation of two parameters, CRP and TNF- $\alpha$, was found in the HPR subgroup in comparison with the LPR group of CABG patients (Table I).

\section{Perioperative outcomes}

Perioperative myocardial infarction and rhythm disturbances occurred more frequently in the high platelet reactivity group (differences close to statistical significance). Post-operative chest bleeding, prolonged ventilator use, renal failure and stroke were similar in both groups. Levels of cardiac markers, EuroSCORE and other clinical parameters were comparable in both tested groups (Table I).

Table II. Characteristics of selected parameters of coronary artery bypass grafting patients $(n=103)$ before and 6 days after operation

\begin{tabular}{|lccc|}
\hline Variable & Before operation & 6 days after operation & $P$-value \\
\hline $\mathrm{Hb}[\mathrm{g} / \mathrm{dl}]$ & $13.77 \pm 1.01$ & $11.64 \pm 1.21$ & $<0.0001$ \\
\hline Leukocyte count $\left[\times 10^{9} / \mathrm{l}\right]$ & $8.29 \pm 1.48$ & $10.12 \pm 1.67$ & $<0.0001$ \\
\hline Platelet count $\left[\times 10^{9} / \mathrm{l}\right]$ & $187.0 \pm 50.1$ & $229.2 \pm 81.3$ & $<0.0001$ \\
\hline Mean platelet volume $[\mathrm{fl}]$ & $9.71 \pm 1.84$ & $10.36 \pm 1.57$ & $<0.003$ \\
\hline Tnl $[\mathrm{ng} / \mathrm{ml}]$ & $0.22(0.10-1.36)$ & $0.89(0.32-2.80)$ & $<0.0001$ \\
\hline CK-MB $[\mathrm{UI} / \mathrm{l}]$ & $18.00(13.75-28.00)$ & $25.00(18.00-43.00)$ & $<0.0001$ \\
\hline CRP $[\mathrm{mg} / \mathrm{l}]$ & $16.05(7.57-35.50)$ & $54.05(36.98-)$ & $<0.0001$ \\
\hline TNF- $\alpha[\mathrm{pg} / \mathrm{l}]$ & $1.83(1.07-2.38)$ & $2.63(2.19-4.10)$ & $<0.0001$ \\
\hline IL-6 $[\mathrm{pg} / \mathrm{l}]$ & $8.85(4.90-17.5)$ & $21.87(14.28-34.41)$ & $<0.0001$ \\
\hline
\end{tabular}

Continuous data are presented as mean $\pm S D$ or as median (interquartile range: $L Q-U Q$ ). Categorical data are presented as absolute numbers (n) and \%. Significance of differences was analyzed using Mann-Whitney $U$ test (continuous data) or Fisher's exact test (categorical data). $\mathrm{Hb}$ - hemoglobin, Tnl - troponin I, CRP - C-reactive protein, TNF- $\alpha$ - tumour necrosis factor- $\alpha$, IL-6 - interleukin-6. 
A

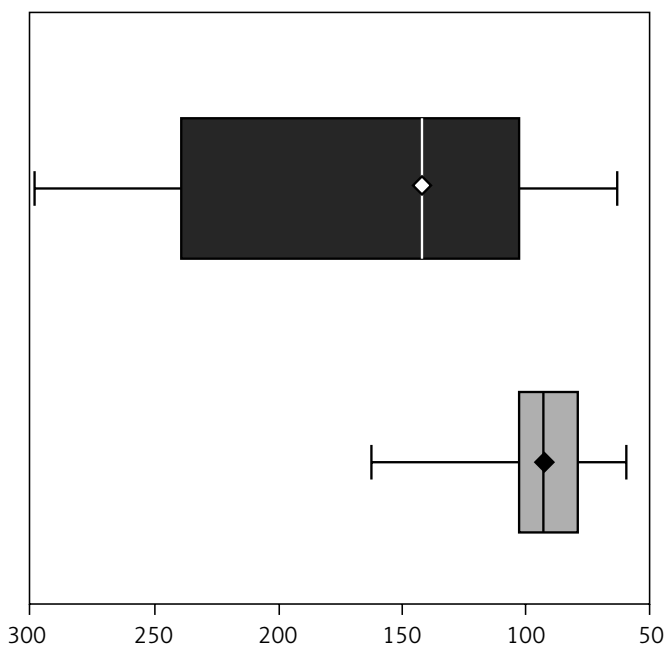

B

6 days after surgery

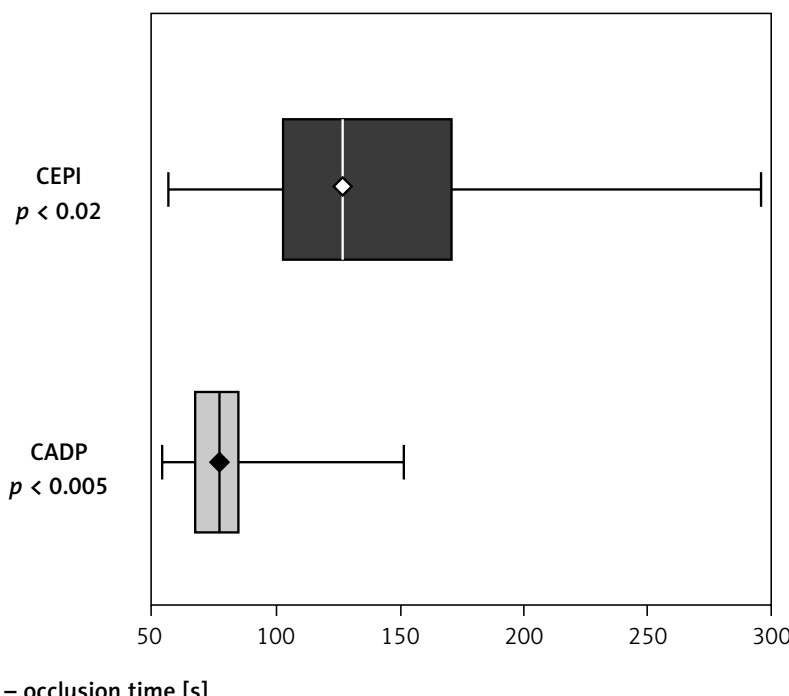

C

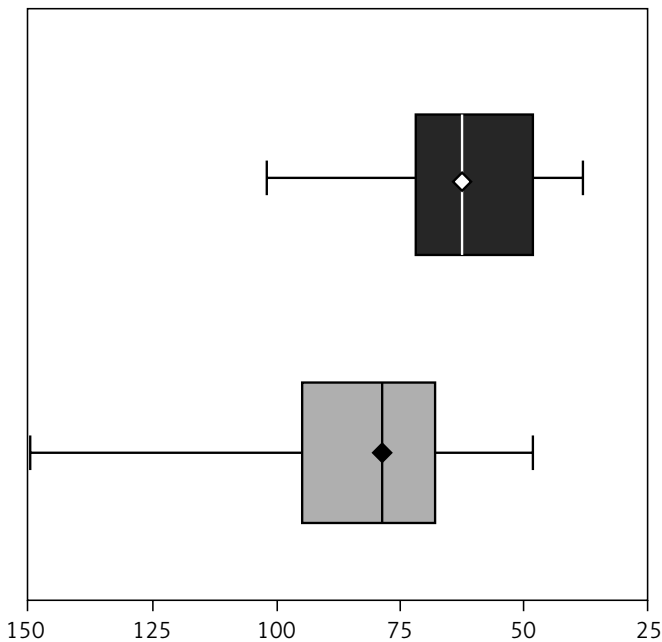

D

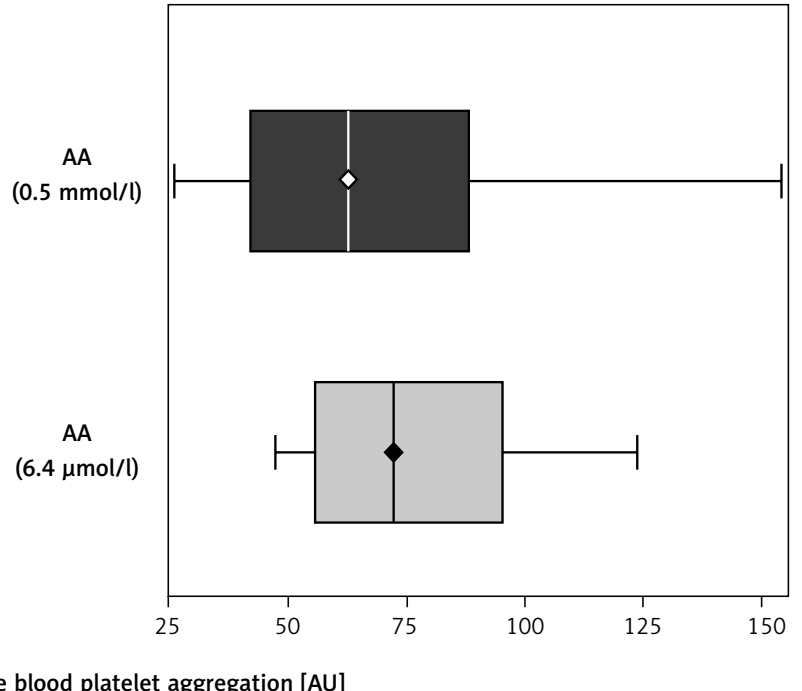

Figure 1. Platelet reactivity monitored in coronary artery bypass grafting (CABG) patients using PFA-100 and Multiplate (MEA - multiple electrode aggregometry) on the day before surgery and $6^{\text {th }}$ day after surgery. Data shown as median (interquartile range, minimum and maximum values). Significance of differences was analysed using the Mann-Whitney $U$ test

Agreement and regression analysis of selected inflammatory markers with platelet reactivity or activation on the $6^{\text {th }}$ day after CABG

A significant association was found between CRP, TNF- $\alpha$, IL- 6 and platelet reactivity (platelet reactivity score) but not with platelet activation (sCD40L, sP-selectin). The agreement between the results was assessed using Cohen's $\kappa$ test and is presented in Table III. Concordance between platelet reactivity and inflammatory markers was in the poor to fair range but reached a level of statistical significance.
A logistic regression analysis showed that CRP and TNF- $\alpha$ were associated with platelet reactivity (Table IV).

\section{Discussion}

The inflammatory milieu that occurs after CABG as a result of cardiopulmonary bypass has been extensively studied and is the consequence of multiple factors, including surgical trauma, and blood contact with the foreign surfaces of the CPB $[5,17]$. On the other hand, the relationship between inflammatory state, CABG and high platelet reactivity has rarely been discussed $[20,24]$. There- 
A

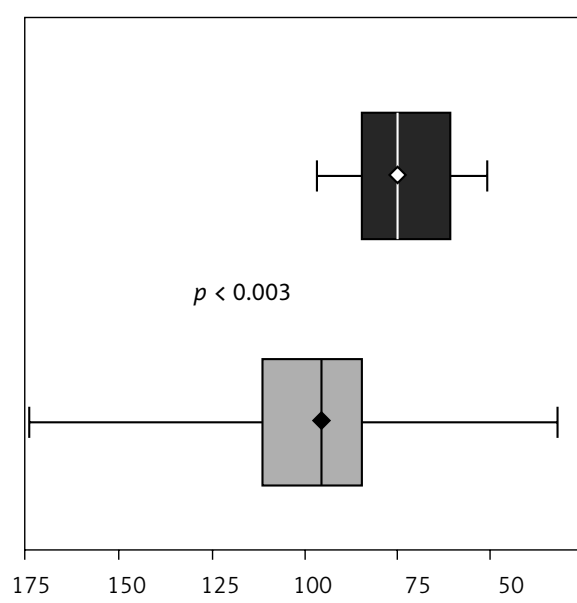

B

SCD40L

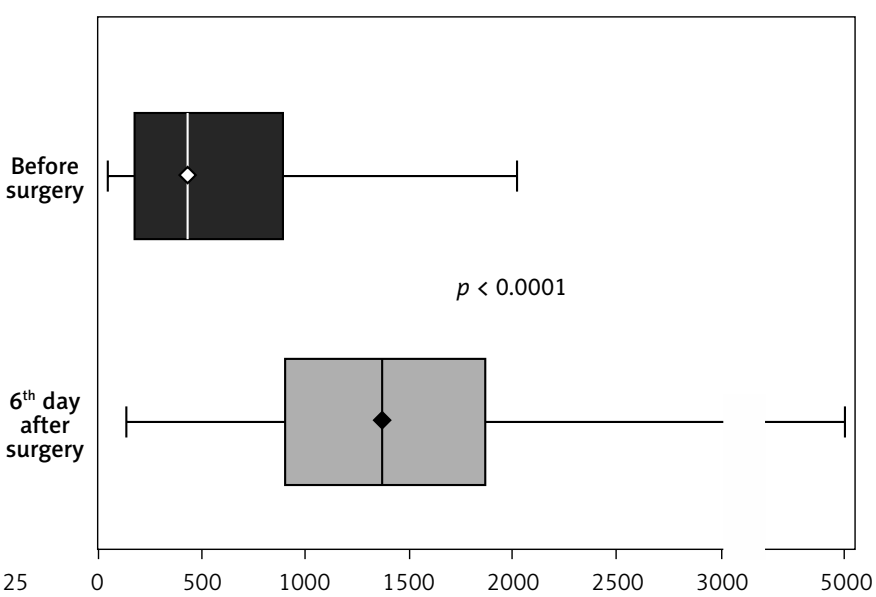

Platelet activation $[\mathrm{pg} / \mathrm{ml}]$

Figure 2. Platelet activation monitored in coronary artery bypass grafting (CABG) patients using immunoassays for soluble P-selectin and soluble CD40L on the day before surgery and $6^{\text {th }}$ day after surgery. Data shown as median (interquartile range, minimum and maximum values). Significance of differences was analysed using the Mann-Whitney $U$ test

Table III. Agreement of selected inflammatory markers with platelet reactivity on $6^{\text {th }}$ day after coronary artery bypass grafting

\begin{tabular}{|lcccc|}
\hline Markers & Observed agreement [\%] & Cohen's $\kappa$ & Confidence interval $(95 \% \mathrm{Cl})$ & $P$-value \\
\hline CRP & 74.5 & 0.49 & $0.246-0.738$ & $<0.0001$ \\
\hline TNF- $\alpha$ & 68.3 & 0.37 & $0.019-0.612$ & $<0.002$ \\
\hline IL-6 & 61.9 & 0.24 & $-0.011-0.432$ & $<0.03$ \\
\hline
\end{tabular}

CRP - C-reactive protein, TNF- $\alpha$ - tumour necrosis factor- $\alpha$, IL-6 - interleukin- 6.

Table IV. Logistic regression analysis to assess the correlation between PRS and inflammatory markers with platelet reactivity on $6^{\text {th }}$ day after coronary artery bypass grafting

\begin{tabular}{|lccc|}
\hline Markers & $\begin{array}{c}\text { Odds ratio } \\
(\text { OR })\end{array}$ & $\begin{array}{c}\text { Confidence interval } \\
(95 \% \mathrm{Cl})\end{array}$ & $P$-value \\
\hline CRP & 1.1049 & $1.046-1.158$ & $<0.003$ \\
\hline TNF- $\alpha$ & 1.225 & $1.119-1.312$ & $<0.03$ \\
\hline
\end{tabular}

$C R P-C$-reactive protein, TNF- $\alpha$ - tumour necrosis factor- $\alpha$.

fore, the aim of this study was to analyse the association between platelet reactivity or platelet activation after CABG with selected markers of the inflammatory state. In our work, the simultaneous use of Multiplate and PFA-100 analysers and the PRS proved to be useful tools for detecting a connection between platelet reactivity and an inflammatory state.

Literature reports that high platelet reactivity after CABG has an incidence range of 10-90\% $[21,25]$. This is a transient phenomenon, more frequently observed during the first month after surgery, and some authors suggest that it may explain the elevated risk of graft thrombosis and death after CABG [2, 21]. The response of platelets to CPB is complex, with a reduction in platelet count from a baseline during the first days, and then increasing to a higher count than before surgery [ 1 , $13,26,27]$. Cardiopulmonary bypass also causes a systemic inflammatory response and platelet activation [26]. Plasma levels of IL-6 significantly correlate with a systemic inflammatory response and reflect the severity of acute inflammation [24].

In this study, we found that the increased platelet reactivity was significantly associated with high levels of CRP, TNF and IL-6, but only when platelet reactivity was expressed as a complex PRS. We observed a significant increase in CRP level during the first week after CABG, peaking at the same time as the lowest anti-platelet therapy effectiveness was recorded. This phenomenon might account for the increased risk of occlusion of bypass grafts at this moment during the post-operative period $[28,29]$. Measurements of residual platelet reactivity by PFA-100 [28] and whole blood platelet aggregometry [30] are considered adequate for predicting risks of cardiovascular events.

We found that perioperative myocardial infarction and rhythm disturbances occurred more fre- 
quently in the high platelet reactivity group. By contrast, basal platelet activation was not associated with inflammatory markers in this study. In the literature, perioperative myocardial infarction and rhythm disturbances were observed but they have rarely been correlated with the inflammatory state and platelet reactivity [31-33]. Interestingly, Plicner et al. showed that clinical outcomes in the early postoperative period are associated with inflammation and platelet activation markers [20].

In our study, all patients displayed a rise in platelet reactivity, despite continuing the same antiplatelet treatment after surgery. The reduced antiplatelet effect of aspirin is associated with low-grade inflammation in patients with coronary artery disease [34]. In our study, we observed a similar tendency in CABG patients. Recent literature has confirmed that CRP promotes platelet activation [35]. Additionally, CRP was found in platelet aggregates and stimulated further platelet deposition at the arterial wall [36]. Moreover, an association was also observed between increased IL6 levels and increased platelet count.

In this study, we demonstrated the platelet hyperreactivity as measured by PFA-100 $\mathrm{CT}_{\text {CADP }}$ (cartridges with ADP and collagen) and by aggregometry (multiplate with ADP as agonist). Interestingly, Gluckman et al. suggested platelet hyperreactivity measured by PFA-100 CT $\mathrm{CADP}_{\text {Po }}$ to a novel independent risk factor for early thrombosis after CABG surgery [28].

In our opinion, application of the PRS with a cutoff at PRS $>2$ indicating platelet hyperactivity allows one to investigate complex dependencies between platelet reactivity and inflammatory state after CABG despite a small number of patients. We believe that the association between inflammatory state and platelet hyperreactivity as well as perioperative outcomes, demonstrated in this study, suggests a need of a combined analysis of both platelet reactivity and inflammatory markers (in particular CRP) in order to assess perioperative outcomes.

In conclusion, our study demonstrated that increased platelet reactivity, expressed as a novel PRS after CABG, is associated with a higher concentration of inflammation markers. Furthermore, following a cardiac operation with extra-corporeal circulation, platelet hyperreactivity in the early post-operative period, combined with a systemic inflammatory state, correlates with a higher risk of post-operative rhythm disturbances.

\section{Conflict of interest}

The authors declare no conflict of interest.

\section{References}

1. Gielen CLI, Brand A, van Heerde WL, Stijnen T, Klautz RJM, Eikenboom J. Hemostatic alterations during coronary artery bypass grafting. Thromb Res 2016; 140: 140-6.

2. Wilczynski M, Wybraniec MT, Milewski K, et al. Eptifibatide infusion versus placebo in high risk patients with non-ST segment elevation acute coronary syndromes managed with urgent coronary artery bypass graft surgery. A prospective multicenter randomized placebo-controlled clinical trial. J Cardiovasc Surg 2016; 57: 100-10.

3. Bomb R, Oliphant CS, Khouzam RN. Dual antiplatelet therapy after coronary artery bypass grafting in the setting of acute coronary syndrome. Am J Cardiol 2015; 116: 148-54.

4. Yang D, Peng C, Liao Z, Wang X, Guo W, Li J. The effect of the CYP2C19*2 allele on cardiovascular outcomes in patients with coronary artery stenting: a prospective study. Arch Med Sci 2018; 15: 837-44.

5. Januszek R, Siudak Z, Dziewierz A, Rakowski T, Dudek D, Bartuś S. Long-term outcomes of percutaneous coronary interventions within coronary artery bypass grafts. Arch Med Sci 2021; 17: 628-37.

6. Agarwal N, Mahmoud AN, Patel NK, et al. Meta-analysis of aspirin versus dual antiplatelet therapy following coronary artery bypass grafting. Am J Cardiol 2018; 121: 32-40.

7. Łabuz-Roszak B, Pierzchała K, Niewiadomska E, Skrzypek M, Machowska-Majchrzak A. Searching for factors associated with resistance to acetylsalicylic acid used for secondary prevention of stroke. Arch Med Sci 2015; 11: 106-14.

8. Jäger B, Piackova E, Haller PM, et al. Increased platelet reactivity in dyslipidemic patients with coronary artery disease on dual anti-platelet therapy. Arch Med Sci 2018; 15: 65-71.

9. Kuliczkowski W, Golanski R, Bijak M, et al. Relationship between high on aspirin platelet reactivity and oxidative stress in coronary artery by-pass grafted patients. Blood Coagul Fibrinolysis 2016; 27: 151-5.

10. Guirgis M, Thompson P, Jansen S. Review of aspirin and clopidogrel resistance in peripheral arterial disease. J Vasc Surg 2017; 66: 1576-86.

11. Jager B, Piackova E, Haller PM, et al. Increased platelet reactivity in dyslipidemic patients with coronary artery disease on dual anti-platelet therapy. Arch Med Sci 2019; 15: 65-71.

12. Sibbing D, Aradi D, Alexopoulos D, et al. Updated expert consensus statement on platelet function and genetic testing for guiding P2Y12 receptor inhibitor treatment in percutaneous coronary intervention. JACC Cardiovasc Interv 2019; 12: 1521-37.

13. Xu K, Chan NC, Hirsh J, et al. Quantifying immature platelets as markers of increased platelet production after coronary artery bypass grafting surgery. Eur J Haematol 2018; 101: 362-7.

14. Schneider DJ, Chava S. Factors influencing platelet reactivity in patients undergoing coronary artery bypass surgery. Coron Artery Dis 2016; 27: 185-90.

15. Cornara S, Crimi G, Somaschini A, et al. Systemic inflammatory status is associated with increased platelet reactivity in the early period after acute coronary syndromes. Platelets 2018; 29: 528-30.

16. Patti G, Mangiacapra F, Ricottini E, et al. Correlation of platelet reactivity and C-reactive protein levels to occurrence of peri-procedural myocardial infarction in patients undergoing percutaneous coronary intervention (from the ARMYDA-CRP study). Am J Cardiol 2013; 111: 1739-44. 
17. Leyvi G, Vivek K, Sehgal S, et al. A comparison of inflammatory responses between robotically enhanced coronary artery bypass grafting and conventional coronary artery bypass grafting: implications for hybrid revascularization. J Cardiothorac Vasc Anesth 2018; 32: 251-8.

18. Weymann A, Popov AF, Sabashnikov A, et al. Baseline and postoperative levels of $\mathrm{C}$-reactive protein and interleukins as inflammatory predictors of atrial fibrillation following cardiac surgery: a systematic review and meta-analysis. Kardiol Pol 2018; 76: 440-51.

19. Evora PR, Bottura C, Arcencio L, Albuquerque AA, Évora PM, Rodrigues AJ. Key points for curbing cardiopulmonary bypass inflammation. Acta Cir Bras 2016; 31 Suppl 1: 45-52.

20. Plicner D, Stolinski J, Wasowicz M, et al. Preoperative values of inflammatory markers predict clinical outcomes in patients after CABG, regardless of the use of cardiopulmonary bypass. Indian Heart J 2016; 68 Suppl 3: S10-5.

21. Golanski J, Chlopicki S, Golanski R, Gresner P, Iwaszkiewicz A, Watala C. Resistance to aspirin in patients after coronary artery bypass grafting is transient - Impact on the monitoring of aspirin antiplatelet therapy. Ther Drug Monit 2005; 27: 484-90.

22. Hedman A, Larsson PT, Alam M, Wallen NH, Nordlander R, Samad BA. CRP, IL- 6 and endothelin- 1 levels in patients undergoing coronary artery bypass grafting. Do preoperative inflammatory parameters predict early graft occlusion and late cardiovascular events? Int I Cardiol 2007; 120: 108-14.

23. Balciunas M, Bagdonaite L, Samalavicius R, Griskevicius L Vuylsteke A. Pre-operative high sensitive C-reactive protein predicts cardiovascular events after coronary artery bypass grafting surgery: a prospective observational study. Ann Card Anaesth 2009; 12: 127-32.

24. Arazi HC, Doiny DG, Torcivia RS, et al. Impaired anti-platelet effect of aspirin, inflammation and platelet turnover in cardiac surgery. Interact Cardiovasc Thorac Surg 2010; 10: 863-7.

25. Wand S, Adam EH, Wetz AJ, et al. The prevalence and clinical relevance of ASA nonresponse after cardiac surgery: a prospective bicentric study. Clin Appl Thromb Hemost 2018; 24: 179-85.

26. Olechowski B, Khanna V, Mariathas M, et al. Changes in platelet function with inflammation in patients undergoing vascular surgery. Platelets 2019; 30: 190-8.

27. Ivert T, Dalen $M$, Ander C, Stålesen R, Lordkipanidzé $M$, Hjemdahl P. Increased platelet reactivity and platelet-leukocyte aggregation after elective coronary bypass surgery. Platelets 2019; 30: 975-81.

28. Gluckman TJ, McLean RC, Schulman SP, et al. Effects of aspirin responsiveness and platelet reactivity on early vein graft thrombosis after coronary artery bypass graft surgery. J Am Coll Cardiol 2011; 57: 1069-77.

29. Chakos A, Jbara D, Singh K, Yan TD, Tian DH. Network meta-analysis of antiplatelet therapy following coronary artery bypass grafting (CABG): none versus one versus two antiplatelet agents. Ann Cardiothorac Surg 2018, 7: 577-85.

30. Rafiq S, Johansson PI, Kofoed KF, et al. Thrombelastographic hypercoagulability and antiplatelet therapy after coronary artery bypass surgery (TEG-CABG trial): a randomized controlled trial. Platelets 2017; 28: 78693.

31. Wang A, Wu A, Wojdyla D, et al. Dual antiplatelet therapy for perioperative myocardial infarction following CABG surgery. Am Heart J 2018; 199: 150-55.
32. Haghjoo M. Postoperative rhythm disorders after adult cardiac surgery. Postoperative Critical Care for Adult Cardiac Surgical Patients. Springer 2018; 405-17.

33. Zakkar M, Ascione R, James AF, Angelini GD, Suleiman MS. Inflammation, oxidative stress and postoperative atrial fibrillation in cardiac surgery. Pharmacol Ther 2015; 154: 13-20.

34. Larsen SB, Grove EL, Kristensen SD, Hvas AM. Reduced antiplatelet effect of aspirin is associated with lowgrade inflammation in patients with coronary artery disease. Thromb Haemost 2013; 109: 920-9.

35. Boncler M, Rywaniak J, Szymanski J, Potempa LA, Rychlik B, Watała C. Modified C-reactive protein interacts with platelet glycoprotein Ibalpha. Pharmacol Rep 2011; 63: 464-75.

36. Badimon L, Pena E, Arderiu G, et al. C-reactive protein in atherothrombosis and angiogenesis. Front Immunol 2018; 9: 430 